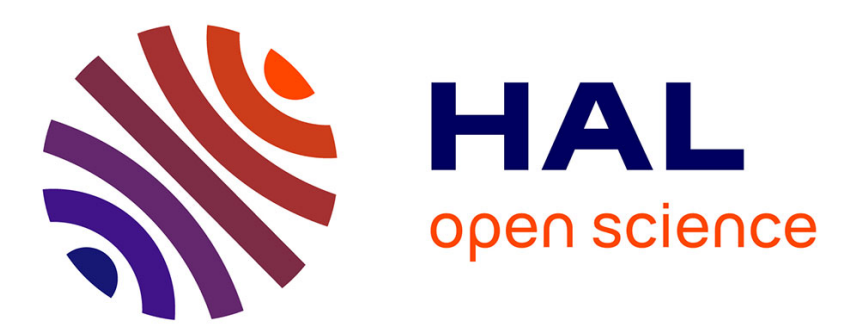

\title{
Physiological responses to chronic heat exposure in an aging non-human primate species, the gray mouse lemur ()
}

\author{
J. Terrien, S. Blanc, P. Zizzari, J. Epelbaum, F. Aujard
}

\section{- To cite this version:}

J. Terrien, S. Blanc, P. Zizzari, J. Epelbaum, F. Aujard. Physiological responses to chronic heat exposure in an aging non-human primate species, the gray mouse lemur (). Experimental Gerontology, 2011, 46 (9), pp.747. 10.1016/j.exger.2011.05.007 . hal-00720176

\section{HAL Id: hal-00720176 https://hal.science/hal-00720176}

Submitted on 24 Jul 2012

HAL is a multi-disciplinary open access archive for the deposit and dissemination of scientific research documents, whether they are published or not. The documents may come from teaching and research institutions in France or abroad, or from public or private research centers.
L'archive ouverte pluridisciplinaire HAL, est destinée au dépôt et à la diffusion de documents scientifiques de niveau recherche, publiés ou non, émanant des établissements d'enseignement et de recherche français ou étrangers, des laboratoires publics ou privés. 


\section{Accepted Manuscript}

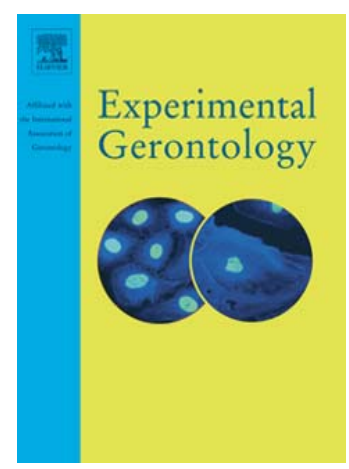

DOI:

S0531-5565(11)00127-6

Physiological responses to chronic heat exposure in an aging non-human primate species, the gray mouse lemur (Microcebus murinus)

J. Terrien, S. Blanc, P. Zizzari, J. Epelbaum, F. Aujard

doi: 10.1016/j.exger.2011.05.007

Reference: $\quad$ EXG 8886

To appear in: $\quad$ Experimental Gerontology

Received date: $\quad 1$ July 2010

Revised date: $\quad 4$ May 2011

Accepted date: $\quad 12$ May 2011

Please cite this article as: Terrien, J., Blanc, S., Zizzari, P., Epelbaum, J., Aujard, F., Physiological responses to chronic heat exposure in an aging non-human primate species, the gray mouse lemur (Microcebus murinus), Experimental Gerontology (2011), doi: $10.1016 /$ j.exger.2011.05.007

This is a PDF file of an unedited manuscript that has been accepted for publication. As a service to our customers we are providing this early version of the manuscript. The manuscript will undergo copyediting, typesetting, and review of the resulting proof before it is published in its final form. Please note that during the production process errors may be discovered which could affect the content, and all legal disclaimers that apply to the journal pertain. 


\section{Physiological responses to chronic heat exposure in an aging non-human} primate species, the gray mouse lemur (Microcebus murinus).

Terrien J. ${ }^{1, a}$, Blanc S. ${ }^{2}$, Zizzari P. ${ }^{3}$, Epelbaum J. ${ }^{3}$, Aujard $\mathbf{F}^{1}$.

${ }^{1}$ Mécanismes Adaptatifs et Évolution, UMR CNRS/MNHN 7179, 1 avenue du Petit Château, Brunoy, France

${ }^{2}$ Institut Pluridisciplinaire Hubert Curien, DEPE UMR CNRS 7178, Université de Strasbourg, Strasbourg, France

${ }^{3}$ Centre de Recherche en Psychiatrie et Neurosciences, UMR 894 INSERM, 4ter rue d'Alésia, 75014 Paris, France

Address correspondence to:

Jérémy TERRIEN

Department of Neuroscience

University of Texas Southwestern Medical Center, Dallas, TX 7539

Lab Phone: 214-648-1979

E-Mail: jeremy.terrien@hotmail.fr

${ }^{a}$ Current address: Department of Neuroscience, University of Texas Southwestern Medical Center, Dallas, TX 75390

Running head: Aging and chronic heat exposure. 


\section{ABSTRACT}

Epidemiological evidence related to increased death from hyperthermia suggests higher frailty in the elderly when exposed to high ambient temperatures. Despite the recent awareness of such public health problems, integrative studies investigating the effects of age on the physiological responses to heat wave thermal conditions remain scarce. Daily rhythmicity of core temperature $\left(\mathrm{T}_{\mathrm{c}}\right)$ and locomotor activity (LA), as well as parameters representative of energy balance and IGF-1 levels which are involved in the aging process and stress resistance, were monitored in a non-human primate species, the gray mouse lemur (Microcebus murinus). Adult and aged animals, acclimated to long days (LD) or short days (SD), were monitored during 8-day periods of exposure to $25^{\circ} \mathrm{C}$ and $34^{\circ} \mathrm{C}$.

Adult animals displayed efficient coping with heat exposure, regardless of the photoperiod. Hence, efficient responses resulted in decrease of energy intake, energy expenditure, IGF-1 levels and LA levels, promoting hyperthermia avoidance. Positive energy balance was maintained and water turnover did not change significantly after heat exposure.

In contrast, while aged animals acclimated to LD responded similarly to adults, aged mouse lemurs acclimated to SD showed great difficulties coping with heat exposure. Indeed, in this group, normothermia impairment was associated with increased $\mathrm{T}_{\mathrm{c}}$ levels, alterations in daily rhythmicity, negative energy balance and increased IGF-1 levels.

Impaired responses to heat exposure were seen in aged mouse lemurs acclimated to SD only. The main effects were observed during diurnal resting periods, suggesting decreased capacities with age to dissipate excess body heat. Taken together, these data highlight daily rhythmicity and IGF-1 pathway as main targets in the impaired response to heat exposure in the elderly. 


\section{Graphical abstract:}

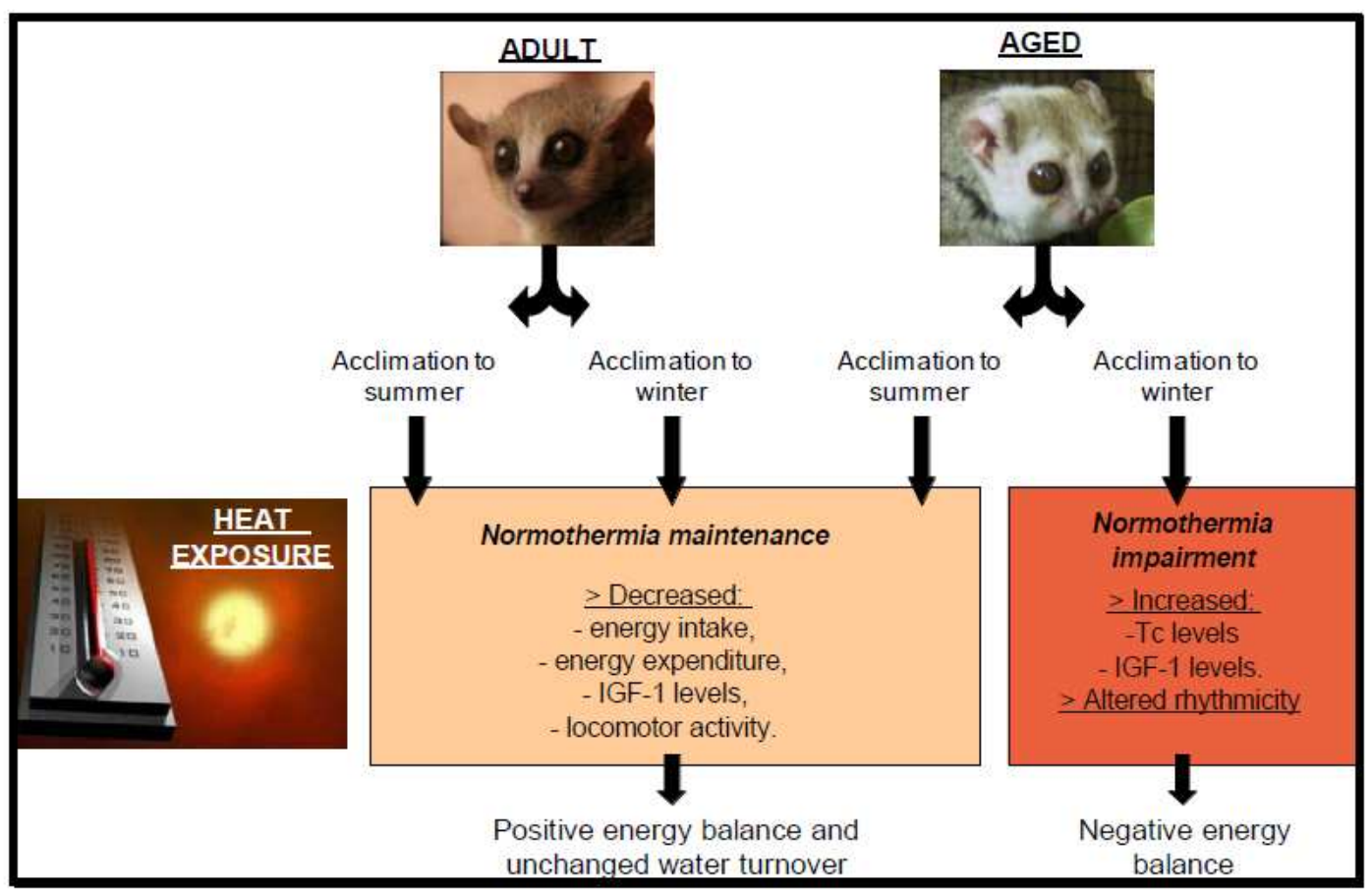

\section{Research highlights:}

- Acclimation to summer prevented adult and aged mouse lemurs from normothermia impairment when exposed to heat exposure.

- Appropriate coping with heat exposure lead to maintenance of positive energy balance and unchanged water turnover.

- Aged mouse lemurs acclimated to winter showed severe normothermia impairment, leading to negative energy balance. 
Key words: heat exposure, core temperature, non-human primate, energy balance, IGF-1, water turnover.

\section{List of abbreviations:}

BM: Body mass

BMG: Body mass gain

CI: Caloric intake

DEE: Daily energy expenditure

IGF-1: Insulin-like growth factor 1

$\mathrm{H}_{\text {decr }}$ : Hour of $\mathrm{T}_{\mathrm{c}}$ decrease

$\mathrm{H}_{\text {min }}$ : Hour of $\mathrm{T}_{\mathrm{c}} \min$

LA: Locomotor activity

LA $_{\text {day }}$ : Locomotor activity during the day

LA $_{\text {night }}$ : Locomotor activity during the night

LD: Long day

LME: Linear mixed effects model

PP: Photoperiod

$\mathrm{T}_{\mathrm{a}}$ : Ambient temperature

$\mathrm{T}_{\mathrm{c}}$ : Core temperature

$\mathrm{T}_{\mathrm{c} \text { day: }}$ Core temperature during the day

$\mathrm{T}_{\mathrm{c} \text { night: }}$ Core temperature during the night

$\mathrm{T}_{\mathrm{c} \text { min: }}$ Minimal value of core temperature 


\section{INTRODUCTION}

The high prevalence for death in the elderly population during the last heat wave events in Europe (Sardon, 2007) points out the frailty of aged humans towards high ambient temperatures $\left(\mathrm{T}_{\mathrm{a}}\right)$. Although hyperthermia risk in the elderly during heat waves is now considered a major public health problem (Kovats and Hajat, 2008), the intrinsic reasons for such impairment are still not well understood. Potential physiological failures, such as impaired cardiovascular capacities (Kenney and Munce, 2003) or increased risks of dehydration (Ferry, 2005) have been identified The effects of global climate change could increase the probability of similar unpredictable heat waves in the future (Luber and McGeehin, 2008), so integrative studies on the responses to long-term heat exposure in the elderly are essential.

To better understand the effects of aging on homeostasis maintenance, we monitored the thermoregulatory responses of a highly photoperiod-responsive species, the gray mouse lemur (Microcebus murinus), during exposure to high $\mathrm{T}_{\mathrm{a}}$. This small nocturnal primate, originating from Madagascar, exhibits robust seasonal rhythms for most of its biological functions, i.e. body mass, body composition, energy metabolism and thermoregulatory capacities. As a result, reproduction is highly synchronized on photoperiod (PP) changes (Perret and Aujard, 2001), the mouse lemur being sexually active exclusively during long days (LD) which corresponds to the season for high food availability and high $\mathrm{T}_{\mathrm{a}}$ (Dammhahn and Kappeler, 2008). Acclimation to short days (SD) leads to gonadal involution and metabolic depression, the animal facing food scarcity and low $\mathrm{T}_{\mathrm{a}}$ (Dammhahn and Kappeler, 2008; Randrianambinina et al., 2003). In the gray mouse lemur under captive conditions, evidence exists for strong interactions between daily rhythms of core temperature $\left(\mathrm{T}_{\mathrm{c}}\right)$ and photoperiod (Aujard et al., 1998), $\mathrm{T}_{\mathrm{a}}$ (Aujard et al., 1998; Seguy and Perret, 2005; Terrien et al., 2008; Terrien et al., 2009b) and food availability (Giroud et al., 2008; Seguy and Perret, 2005). This 
nocturnal primate species [mean life span in captivity around 6 years (Perret, 1997)] has become popular during the past decade as a model of aging. Indeed, aging is associated in this species with decreased amplitude of the seasonal variations in body mass and gonadal hormones (Aujard and Perret, 1998), melatonin (Aujard et al., 2001), and DHEA-S (Perret and Aujard, 2005). Recent studies investigating the effects of cold exposure in the mouse lemur have showed differential effects of aging on thermoregulatory capacities and energy homeostasis according to photoperiod (Terrien et al., 2009a; Terrien et al., 2008; Terrien et al., 2009b). According to this, we hypothesized that responses to heat exposure could be impaired if the animals are not physiologically predisposed to respond to such stress. In the present integrative study, parameters of energy balance, such as energy intake and expenditure, locomotor activity (LA) levels, and water turnover were monitored in mouse lemurs exposed to chronic heat. Moreover, daily rhythms of $\mathrm{T}_{\mathrm{c}}$ and LA are known to be impaired during aging (Van Someren et al., 2002; Weinert and Waterhouse, 2007) and were also analyzed. Finally, IGF-1 levels, previously described to be associated with longevity and stress resistance (Bonafe and Olivieri, 2009; Murakami, 2006), were measured. Physiological responses to heat stress were assessed in adult and aged mouse lemurs acclimated to LD photoperiod, i.e. physiologically predisposed to experiencing high $\mathrm{T}_{\mathrm{a}}$, and to $\mathrm{SD}$, i.e. not predisposed to such heat exposure.

\section{METHODS}

$\underline{\text { Animals and housing conditions: }}$

All gray mouse lemurs studied were males, born in the laboratory breeding colony of Brunoy (MNHN, France, license approval $\mathrm{N}^{\circ}$ A91.114.1) and were pathogen free. General conditions of captivity were maintained constant: $\mathrm{T}_{\mathrm{a}}\left(24-26^{\circ} \mathrm{C}\right)$, relative humidity $(55 \%)$. Food 
(including fresh fruits and a milky mixture) and water were available ad libitum. In captivity, seasonal variations of physiological functions are entrained by alternating 6-month periods of LD photoperiod (14 h of light / day) and SD photoperiod (10 h of light / day) under artificial light: fluorescent tubes during the day (white light, 250 lux, wavelength peak at $488 \mathrm{~nm}$ ) and dim red light during the night (0.002 lux, wavelength peak at $630 \mathrm{~nm})$. In the present study, male mouse lemurs were studied during both long and short day-lengths, at least two months after the onset of each season. Physiological status of the animals was thus supposed to be stabilized. General conditions of captivity were applied and animals were maintained in social groups before and after experiments. Survival data from 254 male mouse lemurs from our breeding colony were used to determine the mean life span (mean \pm SEM: $6.0 \pm 0.2$ years), the mean life span of the $10 \%$ of the most long-lived animals $(10.0 \pm 0.2$ years $)$ and the observed maximal survival duration (12.0 years). After reaching 5 years of age, mouse lemurs exhibit typical morphological and physiological modifications related to aging: graying of the fur and decreased amplitude in seasonal variations of body mass (Perret, 1997; Perret and Aujard, 2005). Moreover, in the male mouse lemur, both behavioral and physiological parameters of reproductive function clearly decrease with aging after the age of 5 years. Indeed, reductions in aggressive, marking and sexual behaviors are commonly observed in aged mouse lemurs and are concurrent with a decline in sexual hormone levels (Aujard and Perret, 1998; Perret and Aujard, 2005). In the present study, adults ( $\mathrm{N}=7$ during both LD and SD; mean age \pm SEM: $1.6 \pm 0.3$ years, range: $1.0-2.4)$ and aged mouse lemurs $(\mathrm{N}=5$ during LD and $\mathrm{N}=6$ during SD; mean age \pm SEM: $7.4 \pm 0.2$ years, range: $6.4-8.3$ ) were used. All experiments were carried out in accordance with the European Communities Council Directive (86/609/EEC). All efforts were made to minimize nociception.

Core temperature and locomotor activity recording: 
Core temperature $\left(\mathrm{T}_{\mathrm{c}}\right)$ and locomotor activity (LA) were monitored as already described (Terrien et al., 2009a). Briefly, mouse lemurs were acclimated in climatic chambers for a week, then studied for 8 days at the reference $\mathrm{T}_{\mathrm{a}}$ of $25^{\circ} \mathrm{C}$ and finally exposed to heat ( 8 days at $34{ }^{\circ} \mathrm{C}$ ). Light/dark cycles were generated by the alternation of intense white light and dim red light. Using an intra-abdominal transmitter (TA10TA-F20, Data Science Co. Ltd, Minnesota, USA) that never exceeded 3.5\% of animal body mass (Adams et al., 2001), core temperature and activity levels were telemetrically monitored. Data were analyzed using the Dataquest Lab Pro v. 3.0 software (Data Science Co. Ltd, Minnesota, USA). The following parameters were analyzed: mean $T_{c}$ during the active nocturnal phase $\left(T_{c}\right.$ night $)$, mean $T_{c}$ during the resting diurnal phase $\left(T_{c \text { day }}\right)$, the minimal $T_{c}$ value $\left(T_{c \text { min }}\right)$, time of occurrence of $\mathrm{T}_{\mathrm{c} \text { min }}\left(\mathrm{H}_{\mathrm{min}}\right)$ and time of occurrence of the beginning of $\mathrm{T}_{\mathrm{c}}$ decrease $\left(\mathrm{H}_{\mathrm{dec}}\right)$. The last two parameters were expressed in minutes relative to lights on. $\mathrm{H}_{\text {decr }}$ was determined each day as the first time point of a succession of 3 decreases of $T_{c}$. Similarly, $H_{\min }$ was determined each day as the time point occurring at least after $30 \mathrm{~min}$ of decrease and before at least $30 \mathrm{~min}$ of $T_{c}$ increase. Consequently, $T_{c} \min$ corresponded to the $T_{c}$ value pointed at the $H_{\min }$ time point. Finally, LA values were averaged during the nocturnal active phase (LA $\left.A_{\text {night }}\right)$ and the diurnal resting phase $\left(\mathrm{LA}_{\text {day }}\right)$. All telemetric parameters were averaged for each thermal exposure and then analyzed. Actograms were also generated using the Clocklab software (Actimetrics Inc., Evanston, IL). LA onset (in min) was defined as the time of occurrence of the first or last (respectively) 3 successive bins (i.e., the counts of activity per 10 minutes) when activity was greater or lower (respectively) than $\mathrm{LA}_{\text {day. }}$ LA onset and offset were computed in reference to the time of lights-off and lights-on, respectively. The duration of the LA active phase (alpha, in min) corresponded to the time duration between LA onset and offset values. For all temporal parameters, phase advances were expressed by positive values and phase delays by negative values in reference to their respective reference points. All telemetric parameters 
were first analyzed as a day-by-day time course over each thermal exposure, and then averaged for each $\mathrm{T}_{\mathrm{a}}$.

Body mass, caloric intake:

Body Mass (BM) was measured every 2 days throughout the experiment. Body Mass Gain (BMG) was calculated as a mean ratio (in g / day) during the whole exposure. Animals were routinely fed ad libitum on a diet including fresh bananas (393 kJ / $100 \mathrm{~g})$ and a homemade milky mixture containing baby cereals, eggs and milk (435 kJ / 100 g). Daily caloric intake (CI) was calculated by subtracting the remaining food to the total food mass given. CI was expressed in $\mathrm{kJ}$ according to the Diem table (Diem, 1963) and normalized to the BM of the animal (kJ / day * $100 \mathrm{~g} \mathrm{BM})$. The evaporation-related loss was taken into account in the calculation of $\mathrm{CI}$ at each $\mathrm{T}_{\mathrm{a}}$.

\section{Daily energy expenditure and water turnover:}

Daily energy expenditure (DEE) and water turnover were estimated over a period of 3 days by the Doubly Labeled Water (DLW) method as already described. Briefly, the same animal underwent this protocol after 6 days at both 25 and $34^{\circ} \mathrm{C}$. DLW water was injected in the peritoneum according to animal body mass. Isotope equilibration (determined from a blood sample collected 1 hour after injection) and enrichments (determined from urine collected over 3 days after injection) allowed the calculation of total body water (TBW), DEE, and water turnover. DEE was expressed in $\mathrm{kJ} /$ day and water turnover in $\mathrm{g} / \mathrm{day}$.

\section{Plasma IGF-1 levels:}

Blood was taken from all animals at the reference $\mathrm{T}_{\mathrm{a}}$ of $25^{\circ} \mathrm{C}$ and then 2 days (short-term response) and 8 days (long-term response) after the beginning of heat exposure, at a fixed 
time at the end of the diurnal phase. About $100 \mu$ l of blood was drawn from the saphenous vein into heparinized capillaries without anesthesia. After centrifugation, plasma was immediately collected and preserved at $-20{ }^{\circ} \mathrm{C}$ until the radio-immunoassay, which was performed in reference to the manufacturer instructions (Immunotech IGF-I IRMA; Bechman Coulter, Paris, France). Intra- and between-series variation rates were lower than $7 \%$ and minimal detectable values were $2 \mathrm{ng} / \mathrm{ml}$. As $\mathrm{T}_{\mathrm{c}}$ rhythms could be disturbed by animal handling, the telemetric data corresponding to the 4 hours after the blood samples were removed. IGF-1 plasma levels were related to the body mass of the animal studied in accordance to the fact that IGF-1, by its property of growth factor, can interact with body composition, and particularly with body fat (Engstrom et al., 2006; Onder et al., 2006).

\section{$\underline{\text { Statistical analysis }}$}

According to the statistical design, dependent variables were analyzed with Generalized Linear Models (GLM) or with Linear Mixed Effect models (LME), built with the "nlme" function (Pinheiro et al., 2005). All dependent variables were checked for normality and homoscedasticity with models' residuals. $\mathrm{H}_{\min }$ and $\mathrm{DEE}$, which were non-normal variables, were normalized using a square-root transformation. LME were built by taking into account the inter-individual variability. Indeed, the effect of individual identity was declared as a random effect. In addition, since the same individuals were used at $25{ }^{\circ} \mathrm{C}$ and $34{ }^{\circ} \mathrm{C}$, we allowed inter-individual variation to depend on temperature by declaring the slope of the effect of $\mathrm{T}_{\mathrm{a}}$ as a random factor. Statistical models including the additive effects of photoperiod (two levels, $\mathrm{LD}$ versus $\mathrm{SD}$ ), $\mathrm{T}_{\mathrm{a}}$ (two levels, $25^{\circ} \mathrm{C}$ and $34^{\circ} \mathrm{C}$ ) and age (two levels, adult versus aged), and their interaction were constructed. Moreover, when analyzing the time-course of parameters during heat exposure, the effects of duration (8 levels, from day 1 to day 8) and their interactions with other additive effects were tested. Significance of effects 
were assessed by F-tests (Bolker et al., 2009) with software R Version 2.6.0 (R Development Core, 2004). Within categories differences were estimated by performing post-hoc t-tests. Pearson correlations were also performed. Values are presented in the text as mean \pm SEM and considered as significant for $\mathrm{p}<0.05$.

\section{RESULTS}

$\mathbf{T}_{\mathbf{c}}$ levels increased after heat exposure. Heat exposure significantly modified daily $T_{c}$ levels. Indeed, average values of $\mathrm{T}_{\mathrm{c} \text { night, }} \mathrm{T}_{\mathrm{c} \text { day }}$ and $\mathrm{T}_{\mathrm{c} \text { min }}$ increased between 25 and $34{ }^{\circ} \mathrm{C}$, whatever age and photoperiod (Figure 1 - Table 1). However, the observed increase was much higher in SD than in $\mathrm{LD}$, leading to greater values of nocturnal and diurnal $\mathrm{T}_{\mathrm{c}}$ levels at $34{ }^{\circ} \mathrm{C}$ during SD than during LD. During both LD and SD however, only adult mouse lemurs maintained general patterns of daily $\mathrm{T}_{\mathrm{c}}$ rhythms at $34{ }^{\circ} \mathrm{C}$ and still exhibited a daily phase of $\mathrm{T}_{\mathrm{c}}$ drop. Aged mouse lemurs showed the same $\mathrm{T}_{\mathrm{a}}$-induced changes (Figure 1 - Table 1), with greater $\mathrm{T}_{\mathrm{c}}$ differences between 25 and $34{ }^{\circ} \mathrm{C}$ during $\mathrm{SD}$ as compared to adults. In addition, if aged animals still exhibited a daily phase of $\mathrm{T}_{\mathrm{c}}$ drop at $34{ }^{\circ} \mathrm{C}$ during $\mathrm{LD}$, this was not the case during SD.

A significant effect of duration was observed on $T_{c}$ throughout heat exposure, during the day (Figure 2) but not during the night $\left(\mathrm{F}_{(7,160)}=0.91, \mathrm{NS}\right) . \mathrm{T}_{\mathrm{c} \text { day }}$ was markedly increased on day 1 of heat exposure in adults and remained quite stable along the 8-day exposure to $34{ }^{\circ} \mathrm{C}$. Diurnal $\mathrm{T}_{\mathrm{c}}$ levels did not exceed $37.5{ }^{\circ} \mathrm{C}$ throughout the 8-day exposure to $34{ }^{\circ} \mathrm{C}$ (Figure 2). Although age did not affect average $T_{c}$ over the whole time-period (Table 1), significant agerelated changes were revealed on a day-by-day analysis. A greater increase on day 1 of heat exposure can be seen in aged animals only under SD (Figure 2). Moreover, $\mathrm{T}_{\mathrm{c}}$ drastically increased at the onset of exposure to $34^{\circ} \mathrm{C}$ at both photoperiods, but with higher amplitude 
during SD than during LD. While aged animals acclimated to LD were able to stabilize their $\mathrm{T}_{\mathrm{c}}$ around $37.0^{\circ} \mathrm{C}$, values still increased up to $38.1^{\circ} \mathrm{C}$ until day 6 during SD. The same observations were made for $\mathrm{T}_{\mathrm{c} \min }\left(\mathrm{F}_{(1,20)}=4.29, \mathrm{p}<0.05\right)$.

Heat-induced decrease in LA levels. Both nocturnal $\left(F_{(1,23)}=12.6, p<0.01\right)$ and diurnal $(F$ $(1,23)=5.5, \mathrm{p}<0.05)$ levels of LA were affected by $\mathrm{T}_{\mathrm{a}}$. In adult mouse lemurs, mean $24 \mathrm{~h}$ amounts of LA $\left(\mathrm{LA}_{\text {night }}+\mathrm{LA}_{\text {day }}\right)$ decreased between 25 and $34{ }^{\circ} \mathrm{C}$ from $156 \pm 13$ to $133 \pm 44$ a.u. and from $101 \pm 15$ to $70 \pm 22$ a.u. during $L D$ and SD, respectively. $\mathrm{LA}_{\text {night }}$ decreased by $17 \%$ and $35 \%$ after heat exposure during $\mathrm{LD}$ and $\mathrm{SD}$, respectively. $\mathrm{LA}_{\mathrm{day}}$ only decreased by $5 \%$ during LD and by $35 \%$ during SD.

Aged animals exhibited robust drops in $\mathrm{LA}_{\text {night, }}$ averaging $30 \%$ and $50 \%$ during $\mathrm{LD}$ and $\mathrm{SD}$, respectively. $\mathrm{LA}_{\text {day }}$ was also strongly decreased after heat exposure by $45 \%$ and $49 \%$ during $\mathrm{LD}$ and SD, respectively. Mean $24 \mathrm{~h}$ amounts of $\mathrm{LA}\left(\mathrm{LA}_{\mathrm{night}}+\mathrm{LA}_{\text {day }}\right)$ decreased from $112 \pm$ 28 to $76 \pm 14$ a.u. and from $124 \pm 19$ to $77 \pm 18$ a.u. during LD and SD, respectively, between 25 and $34{ }^{\circ} \mathrm{C}$. Although the heat-induced decrease of LA seemed to be higher in aged than in adult animals, this effect did not reach significance for nocturnal $\left(\mathrm{F}_{(1,21)}=0.18\right.$, NS) nor for diurnal $\left(\mathrm{F}_{(1,21)}=0.45, \mathrm{NS}\right)$ LA levels.

\section{Daily rhythmicity of $T_{c}$ and LA were impaired during heat exposure. Heat exposure} modified the daily rhythmicity of $\mathrm{T}_{\mathrm{c}}$ and $\mathrm{LA}$. $\mathrm{H}_{\text {decr }}$ varied according to $\mathrm{T}_{\mathrm{a}} * \mathrm{PP}$ and age $* \mathrm{PP}$ effects. The onset of $\mathrm{T}_{\mathrm{c}}$ decrease occurred later in SD than in LD in reference conditions, whatever the age. $\mathrm{H}_{\text {decr }}$ was advanced (without reaching significance) after heat exposure during LD whereas significantly delayed during SD, each time at a higher extent in aged animals vs. adults (Figure 3). According to Figure 3, the onset of $\mathrm{T}_{\mathrm{c}} \min$ was delayed in aged animals as compared to adult ones, and in LD as compared to SD. However, $\mathrm{H}_{\text {min }}$ occurred 
much later after heat exposure than during reference conditions, without any difference among age or photoperiod groups (Figure 3). Regarding modulations of activity / rest rhythm, the onset of LA was significantly affected by duration * age * PP effect. In adult animals acclimated to LD, LA onset was markedly delayed between $25{ }^{\circ} \mathrm{C}$ and the first day of heat exposure (Figure 4). Then, adult mouse lemurs slowly advanced the beginning of LA throughout the exposure to $34{ }^{\circ} \mathrm{C}$. Such effects were not observed in SD, during which LA onset did not vary significantly (Figure 4). Consequently, LA alpha significantly differed according to duration * PP effect. Indeed, LA alpha decreased on the first day of heat exposure and slightly increased over the 8-day period in adult animals acclimated to LD (Figure 4). LA alpha was not significantly modified after heat exposure during SD. Overall, aged mouse lemurs showed the same variations of LA onset and LA alpha. However, during LD, aged individuals anticipated more lights off than adult ones, and thus exhibited longer periods of activity.

Modulations of energy balance. Heat exposure induced a drastic decrease in CI in all animals, whatever age and photoperiod (Table 2). In adult animals, CI decreased between 25 and $34{ }^{\circ} \mathrm{C}$ by 16 and $43 \%$ during LD and SD, respectively. In aged mouse lemurs, heat exposure reduced levels of CI by 32 and $45 \%$ during LD and SD, respectively. In concomitance with CI decrease, DEE also showed decreased rates between 25 and $34{ }^{\circ} \mathrm{C}$. After heat exposure, BM-corrected DEE decreased by $46 \%$ and $37 \%$ in adult mouse lemurs acclimated to LD and to SD, respectively (Table 2). In aged animals, BM-corrected values of DEE decreased after heat exposure by $34 \%$ in LD and $31 \%$ in SD. Paradoxically, BMG did not vary as BM and DEE did. Indeed, BMG differed according to age * PP effect. In adult animals, BMG increased between 25 and $34{ }^{\circ} \mathrm{C}$ during LD, while remaining stable during SD. 
Aged animals showed stable BMG rates after heat exposure during LD, whereas old mouse lemurs lost weight during SD.

Water turnover. Average values of water turnover were significantly affected by age * PP effect, but not by exposure to heat $\left(\mathrm{F}_{(1,20)}=0.2\right.$, NS). Adult animals showed higher rates of water turnover during SD than during LD, although this difference did not reach significance (Figure 5). Thus, values averaged $27 \pm 5 \mathrm{~g} /$ day and $33 \pm 3 \mathrm{~g} /$ day in adult animals during LD and SD, respectively. In aged individuals, values exhibited during LD were similar to those exhibited by adult individuals and averaged $31 \pm 5 \mathrm{~g} /$ day in aged individuals. However, SD acclimation induced lower rates than during LD in aged mouse lemurs, leading to lower levels of water turnover than adults during SD. Water turnover averaged $24 \pm 2 \mathrm{~g} /$ day in aged mouse lemurs during SD.

Changes in IGF-1 levels. BM corrected levels of IGF-1 were significantly affected by heat exposure and PP and tended to differ according to age $* \mathrm{~T}_{\mathrm{a}} * \mathrm{PP}$ effect $\left(\mathrm{F}_{(2,40)}=3.0, \mathrm{p}=\right.$ 0.06). In adult mouse lemurs acclimated to LD, IGF-1 levels markedly decreased (by $32 \%$ ) between $25{ }^{\circ} \mathrm{C}$ and day 2 at $34{ }^{\circ} \mathrm{C}$ (Figure 6). Interestingly, IGF-1 levels after 2 days of heat exposure were negatively correlated to $H_{\text {decr }}$ values in adult animals $\left(r_{p}=-0.83, p<0.05\right)$, which was not the case in their aged counterparts. In aged mouse lemurs acclimated to LD, heat-induced decrease (6\%) was much less evident than in adults (Figure 6), leading to higher levels of IGF-1 in aged individuals as compared to adults. During SD, basal levels of IGF-1 were lower than during LD and heat exposure did not induce any significant change in adults. In contrast, aged mouse lemurs exhibited increased levels of IGF-1 after 8 days of heat exposure, which led to similar levels of IGF-1 between SD and LD after 8 days of heat 
exposure. In addition, aged mouse lemurs exhibiting the highest levels of IGF-1 after 8 days at $34{ }^{\circ} \mathrm{C}$ were the ones with the highest rates of energy expenditure $\left(r_{p}=0.96, p<0.05\right)$.

\section{DISCUSSION}

To our knowledge, this is the first study that investigates the effects of long-term chronic heat exposure, a fortiori in a non-human primate species. In particular, this work characterized the age-related impairment in energy homeostasis involved in the response to chronic heat and emphasizes the role of physiological plasticity as a major parameter for homeostasis maintenance. Efficient coping with high $\mathrm{T}_{\mathrm{a}}$ was observed when the animals were physiologically predisposed to it, whatever the age. Similar response was also achieved in adults that did not have a physiological predisposition, yet showed efficient physiological and behavioral compensation. Hyperthermia avoidance was associated with positive energy balance, decreased IGF-1 levels and unchanged water turnover. In contrast, heat exposure led to homeostasis impairment characterized by increased $T_{c}$ levels, alterations in daily rhythmicity, negative energy balance and increased IGF-1 levels in aged mouse lemurs that were not prepared to face such stress.

\section{Efficient coping with heat exposure during long days and in short day-acclimated adult} mouse lemurs.

Long-term heat exposure was previously analyzed in piglets (Collin et al., 2001a; Collin et al., 2001b; Collin et al., 2001c; Collin et al., 2002) but these studies never dealt with $\mathrm{T}_{\mathrm{c}}$ rhythms or water status. Numerous studies also investigated the $T_{c}$ responses to short-term exposure to extreme heat stress in rodents (Leon et al., 2005; Ohara et al., 1975; Wright, 1976) or to xeric environmental conditions (Palgi and Haim, 2003; Schwimmer and Haim, 2009), but the 
experimental conditions did not mimic heat waves thermal conditions. The present experimental protocol consisted of monitoring simultaneously $\mathrm{T}_{\mathrm{c}}$ and LA modulations, energy balance, water turnover and IGF-1 levels under conditions of constant mild heat stress.

\section{Body temperature and locomotor activity.}

Efficient coping with heat exposure induced only slight effects on $\mathrm{T}_{\mathrm{c}}$ levels, such as observed in adult mouse lemurs during both $\mathrm{LD}$ and $\mathrm{SD}$, but also in aged animals acclimated to LD. Indeed, animals maintained normothermia, thus preventing $\mathrm{T}_{\mathrm{c}}$ from excessive increase. $\mathrm{A} \mathrm{T}_{\mathrm{c}}$ threshold around $37.3{ }^{\circ} \mathrm{C}$ could correspond to the upper physiological limit for normothermia maintenance and hyperthermia avoidance. Such physiologically efficient coping was associated with decreased levels of nocturnal and diurnal LA displayed by both adult and aged animals. In this way, animals drastically limited the LA-induced source of heat generated, probably in order to avoid hyperthermia, as already described in rats (Clark, 1971). Efficient coping with heat exposure also induced strong modulations in daily rhythmicity of $T_{c}$ and LA. In particular, exposure to heat delayed the occurrence of $T_{c}$ min, probably reflecting the increased time needed for dissipating internal body heat to the environment. The phase advance of LA observed during LD indicated increased difficulties to rest when exposed to heat, but could also be interpreted as a strategy to increase air convection processes on the body surface to optimize heat dissipation.

\section{Energy balance and IGF-1 levels}

As already showed in piglets (Collin et al., 2002), heat exposure induced decreased levels of caloric intake, a strategy that could be attributed to the limitation of diet-induced thermogenesis (Lowell and Bachman, 2003). Energy expenditure was also strongly reduced, which allowed the maintenance of a positive energy balance during heat exposure. In 
addition, heat exposure induced decreased levels of IGF-1 in mouse lemurs acclimated to LD from the beginning of heat stress. This decrease was only slight during SD, in probable relation with the low IGF-1 levels measured at baseline as compared to LD. Such a heatinduced decrease in IGF-1 was already noted in piglets (Collin et al., 2002). Moreover, a decrease in IGF-1 level could be involved in the protective response to heat stress. Indeed, low levels of IGF-1 have been associated with increased resistance to numerous stresses, including heat stress (Murakami, 2006).

\section{Water turnover}

One major threat of heat wave for cellular integrity is dehydration (Fouillet et al., 2006), but no direct effect of heat on water turnover was evidenced in the present study. This result is quite surprising in reference to the heat-induced increase in evaporative loss already described in the mouse lemur (Aujard et al., 1998). Such difference could be explained by the fact that the present protocol dealt with chronic and not acute heat exposure. Thus, mouse lemurs would have had enough time to develop efficient strategies to lower water turnover modulations, such as limiting evaporative water loss by decreasing respiratory rhythm. Moreover, others parameters such as energy intake and expenditure, which both take part in water fluxes, were greatly decreased after heat exposure, thus probably contributing to soften the effects of high $T_{a}$ on water turnover. Nevertheless, no direct conclusion can be drawn and further quantitative investigations on water intake and water loss are needed.

\section{Coping with heat exposure is impaired during short days in aged mouse lemurs.}




\section{Importance of season acclimation}

A clear photoperiod-dependent difference in thermoregulatory capacities was observed in aged mouse lemurs highlighting the importance of seasonal acclimation for such study. The relevance of this observation to humans has been usually underestimated since it is generally admitted that seasonality has been lost in humans. Nevertheless, there is evidence that some mechanisms involved in metabolism and thermoregulation show seasonal variations in humans. Indeed, Plasqui and Westerterp showed in 2004 that energy balance was changed between winter and summer, mainly due to changes in physical activity (Plasqui and Westerterp, 2004). Also, a study from Van Ooijen et al (2004) showed that behavioral adjustments to cold air were changed over seasons in humans.

\section{Impaired daily rhythm of body temperature}

In the mouse lemur, heat-induced hyperthermia was greater in SD than in LD conditions, $\mathrm{T}_{\mathrm{c}}$ levels reaching higher values in aged than in adult animals. More specifically, hyperthermia was enhanced during the phase of daily $\mathrm{T}_{\mathrm{c}}$ drop during $\mathrm{LD}$, with a quasi-disappearance of daily heterothermia under SD photoperiod. Such impairment in aged mouse lemurs could sign decreased ability in coping with heat exposure and thus impaired homeostasis maintenance. Indeed, the increased heat-induced difference in minimal $T_{c}$ levels could be related to altered capacities for dissipating body heat. Strong thermolysis capacities, such as vasodilation and sweating, are necessary to compensate the decreased gradient of temperature between the organism and the environment (Kenney and Munce, 2003). Age-related impairments that involve e.g. sweating and evaporative mechanisms, have already been described in humans (Van Someren et al., 2002). Impaired capacities in heat dissipation as observed in SD conditions could explain the delayed onsets of $\mathrm{T}_{\mathrm{c}}$ decrease and minimal $\mathrm{T}_{\mathrm{c}}$ levels at $34{ }^{\circ} \mathrm{C}$, but the underlying mechanisms remain to be demonstrated in aged mouse lemurs. These 
responses were greater in aged mouse lemurs acclimated to SD as compared to adults and could thus reveal increased frailty towards daily rhythmicity. Impaired synchronization to the light-dark cycle with aging is already well documented (Van Someren et al., 2002; Weinert and Waterhouse, 2007) and heat stress could maximize this rhythmicity impairment in aged mouse lemurs. Nevertheless, although strongly decreased LA levels were observed in adult and aged animals exposed to $34{ }^{\circ} \mathrm{C}$, no effect of heat exposure was evidenced on LA rhythmicity. Overall, major effects of heat exposure on $T_{c}$ levels were revealed during diurnal resting periods, suggesting that sleep could represent the most critical period in the day for heat resistance.

\section{Energy imbalance and impaired IGF-1 signaling}

Acclimation to SD revealed impaired management of energy balance after heat exposure during aging. Aged animals did not reduce DEE (-31\%) as much as they decreased CI (-45\%). This imbalance lead to body mass loss at $34{ }^{\circ} \mathrm{C}$ in aged mouse lemurs, suggesting that heat resistance in aged animals was associated with greater energy expenditure during SD than during LD. This is in agreement with previously published results in humans, showing that age affected the rate of heat gain (Inbar et al., 2004). This imbalance would rely on physiological rather than behavioral failure, if considering that aged mouse lemurs adjusted their locomotor activity and caloric intake as well as adults. In addition, age-related failures to protect daily rhythmicity and energy balance were correlated to high levels of IGF-1 during SD, reinforcing the relationship between daily rhythmicity, metabolism and IGF-1 regulation in the response to heat stress. Owing to the recently demonstrated role of decreased IGF-1 signaling in protecting from proteo-toxicity (Cohen et al., 2010; Cohen et al., 2009), the present results suggest that aged mouse lemurs would be more fragile when faced with heat stress due to their high levels of IGF-1. This confirms the role of IGF-1 signaling in 
protection against environmental stressors, and could be of high interest in the elderly, particularly in the context of developing strategies against neurodegenerative diseases such as Alzheimer's disease.

Impaired vasomotor capacities as an explanation for increased frailty towards heat during aging.

Although vasomotor capacities have never been studied in the mouse lemur per se, there are indicators suggesting age-related impairment in heat exchange capacities in the mouse lemur. Since those impairments occurred when animals were acclimated to a winter-like photoperiod, we could speculate that subcutaneous fat would have contributed to impaired heat exchanges. Indeed, many mammals increase their subcutaneous fat layer to promote their insulation capacities during winter to face low $\mathrm{T}_{\mathrm{a}}$ (Heldmaier et al., 1985; Meagher et al., 2008). Because we could not detect any change in body composition with age (data non published) and knew that adults also show greater subcutaneous fat deposits during winter than during summer without major differences in their response to heat, heat exchange impairments observed in the present study might be more likely related to decreased vasomotor capacities. A recent study showed that cold exposure induced very low levels of $\mathrm{T}_{\mathrm{c}}$ associated with negative energy balance in aged mouse lemurs (Terrien et al., 2009a). In addition, another study enhancing heat production after isoproterenol injection showed blunted rise in skin temperature associated with sustained oxygen consumption (Terrien et al., 2010). Taken together, these results suggest that vasomotor capacities are impaired with age in the mouse lemur. Impaired mechanisms of heat dissipation have been demonstrated in aged humans (Inbar et al., 2004). In the mouse lemur, increased heat-induced difference in minimal $\mathrm{T}_{\mathrm{c}}$ levels could be related to altered capacities for dissipating body heat. Moreover, melatonin has been described to facilitate heat loss (Cagnacci et al., 1997) and its secretion is known to 
be decreased with age in the mouse lemur (Aujard et al., 2001). This could contribute to the age-related failure to handle heat stress in this species.

Conclusions and perspectives. Efficient coping with heat exposure resulted in normothermia maintenance, concomitant decreased levels of CI and energy expenditure. Positive energy balance was maintained positive and animals prevented dehydration by efficiently managing their water turnover. Acclimation to $L D$, i.e. the photoperiod corresponding to high $T_{a}$ conditions in the wild, induced appropriate management of heat stress. During SD however, adult were the only individuals that were able to behaviorally and physiologically adjust to protect their homeostasis maintenance. In contrast, aging was associated with decreased ability to cope with heat exposure during SD, especially during resting periods. Daily rhythmicity of $T_{c}$ was particularly altered during heat exposure. Such effects on $T_{c}$ levels were associated with increased levels of IGF-1 and negative energy balance, probably revealing decreased capacities for dissipating excess body heat. These data suggest that daily rhythmicity and IGF-1 pathway should be further investigated as main targets in the impaired response to heat exposure in the elderly.

\section{ACKNOWLEDGEMENTS}

This work was conducted with the financial support of the Institut de la Longévité et du Vieillissement, the Fondation pour la Recherche Médicale (FRM) and the ANR- Agence Nationale de la Recherche - The French National Research Agency under the Programme National de Recherche en Alimentation et nutrition humaine, project ANR-06-PNRA-010-01. 


\section{REFERENCES}

Adams, C.S., Korytko, A.I., Blank, J.L., 2001. A novel mechanism of body mass regulation. Journal of Experimental Biology 204, 1729-34.

Aujard, F., Dkhissi-Benyahya, O., Fournier, I., Claustrat, B., Schilling, A., Cooper, H.M., Perret, M., 2001. Artificially accelerated aging by shortened photoperiod alters early gene expression (Fos) in the suprachiasmatic nucleus and sulfatoxymelatonin excretion in a small primate, Microcebus murinus. Neuroscience 105, 403-12.

Aujard, F., Perret, M., 1998. Age-related effects on reproductive function and sexual competition in the male prosimian primate, Microcebus murinus. Physiology \& Behavior 64, 513-9.

Aujard, F., Perret, M., Vannier, G., 1998. Thermoregulatory responses to variations of photoperiod and ambient temperature in the male lesser mouse lemur: a primitive or an advanced adaptive character? Journal of Comparative Physiology B-Biochemical Systemic and Environmental Physiology 168, 540-8.

Bolker, B.M., Brooks, M.E., Clark, C.J., Geange, S.W., Poulsen, J.R., Stevens, M.H., White, J.S., 2009. Generalized linear mixed models: a practical guide for ecology and evolution. Trends in Ecology \& Evolution 24, 127-35.

Bonafe, M., Olivieri, F., 2009. Genetic polymorphism in long-lived people: Cues for the presence of an insulin/IGF-pathway-dependent network affecting human longevity. Molecular and Cellular Endocrinology 299, 118-123.

Cagnacci, A., Krauchi, K., WirzJustice, A., Volpe, A., 1997. Homeostatic versus circadian effects of melatonin on core body temperature in humans. Journal of Biological Rhythms 12, 509-517.

Clark, R.V., 1971. Behavioral thermoregulation by the white rat at high ambient temperatures. The journal of experimental zoology 178, 387-92.

Cohen, E., Du, D.G., Joyce, D., Kapernick, E.A., Volovik, Y., Kelly, J.W., Dillin, A., 2010. Temporal requirements of insulin/IGF-1 signaling for proteotoxicity protection. Aging Cell 9, 126-134.

Cohen, E., Paulsson, J.F., Blinder, P., Burstyn-Cohen, T., Du, D.G., Estepa, G., Adame, A., Pham, H.M., Holzenberger, M., Kelly, J.W., Masliah, E., Dillin, A., 2009. Reduced IGF-1 Signaling Delays Age-Associated Proteotoxicity in Mice. Cell 139, 1157-1169.

Collin, A., Lebreton, Y., Fillaut, M., Vincent, A., Thomas, F., Herpin, P., 2001a. Effects of exposure to high temperature and feeding level on regional blood flow and oxidative capacity of tissues in piglets. Experimental Physiology 86, 83-91.

Collin, A., van Milgen, J., Dubois, S., Noblet, J., 2001b. Effect of high temperature on feeding behaviour and heat production in group-housed young pigs. British journal of nutrition $86,63-70$.

Collin, A., van Milgen, J., Le Dividich, J., 2001c. Modelling the effect of high, constant temperature on food intake in young growing pigs. Journal of Animal Science 72, 519-527.

Collin, A., Vaz, M.J., Le Dividich, J., 2002. Effects of high temperature on body temperature and hormonal adjustments in piglets. Reproduction Nutrition Development 42, 45-53.

Dammhahn, M., Kappeler, P., 2008. Comparative Feeding Ecology of Sympatric Microcebus berthae and M-murinus. International Journal of Primatology 29, 1567-1589.

Diem, K., 1963. Les vitamines liposolubles, Tables scientifiques. K. Geigy (Eds), Bâle, pp. 459-463.

Engstrom, B.E., Burman, P., Holdstock, C., Ohrvall, M., Sundbom, M., Karlsson, F.A., 2006. Effects of gastric bypass on the GH/IGF-I axis in severe obesity - and a comparison with GH deficiency. European Journal of Endocrinology 154, 53-59. 
Ferry, M., 2005. Strategies for ensuring good hydration in the elderly. Nutrition reviews 63, S22-9.

Fouillet, A., Rey, G., Laurent, F., Pavillon, G., Bellec, S., Guihenneuc-Jouyaux, C., Clavel, J., Jougla, E., Hemon, D., 2006. Excess mortality related to the August 2003 heat wave in France. International Archives of Occupational and Environmental Health 80, 16-24.

Giroud, S., Blanc, S., Aujard, F., Bertrand, F., Gilbert, C., Perret, M., 2008. Chronic food shortage and seasonal modulations of daily torpor and locomotor activity in the grey mouse lemur (Microcebus murinus). American Journal of Physiology-Regulatory Integrative and Comparative Physiology 294, R1958-67.

Heldmaier, G., Böckler, H., Buchberger, A., Lynch, G.R., Puchalski, W., Steinlechner, S., Wiesinger, H., 1985. Seasonal acclimation and thermogenesis, in: Gilles, R. (Ed.), Circulation, Respiration, and Metabolism. Springer-Verlag, Berlin, pp. 490-501.

Inbar, O., Morris, N., Epstein, Y., Gass, G., 2004. Comparison of thermoregulatory responses to exercise in dry heat among prepubertal boys, young adults and older males. Experimental Physiology 89, 691-700.

Kenney, W.L., Munce, T.A., 2003. Invited review: aging and human temperature regulation. Journal of Applied Physiology 95, 2598-603.

Kovats, R.S., Hajat, S., 2008. Heat stress and public health: a critical review. Annual review of public health $29,41-55$.

Leon, L.R., DuBose, D.A., Mason, C.W., 2005. Heat stress induces a biphasic thermoregulatory response in mice. American Journal of Physiology-Regulatory Integrative and Comparative Physiology 288, R197-204.

Lowell, B.B., Bachman, E.S., 2003. Beta-Adrenergic receptors, diet-induced thermogenesis, and obesity. Journal of biological chemistry 278, 29385-8.

Luber, G., McGeehin, M., 2008. Climate change and extreme heat events. American journal of preventive medicine 35, 429-35.

Meagher, E.M., McLellan, W.A., Westgate, A.J., Wells, R.S., Blum, J.E., Pabst, D.A., 2008. Seasonal patterns of heat loss in wild bottlenose dolphins (Tursiops truncatus). J Comp Physiol B 178, 529-43.

Murakami, S., 2006. Stress resistance in long-lived mouse models. Experimental Gerontology.

Ohara, K., Furuyama, F., Isobe, Y., 1975. Prediction of survival time of rats in severe heat. Journal of applied physiology 38, 724-9.

Onder, G., Liperoti, R., Russo, A., Soldato, M., Capoluongo, E., Volpato, S., Cesari, M., Ameglio, F., Bernabei, R., Landi, F., 2006. Body mass index, free insulin-like growth factor I, and physical function among older adults: results from the ilSIRENTE study. American Journal of Physiology-Endocrinology and Metabolism 291, E829-E834.

Palgi, N., Haim, A., 2003. Thermo regulatory and osmoregulatory responses to dehydration in the bushy-tailed gerbil Sekeetamys calurus. Journal of Arid Environments 55, 727-736.

Perret, M., 1997. Change in photoperiodic cycle affects life span in a prosimian primate (Microcebus murinus). Journal of Biological Rhythms 12, 136-45.

Perret, M., Aujard, F., 2001. Regulation by photoperiod of seasonal changes in body mass and reproductive function in gray mouse lemurs (Microcebus murinus): Differential responses by sex. International Journal of Primatology 22, 5-24.

Perret, M., Aujard, F., 2005. Aging and season affect plasma dehydroepiandrosterone sulfate (DHEA-S) levels in a primate. Experimental Gerontology 40, 582-7.

Pinheiro, J., Bates, D., DebRoy, S., Sarkar, D., 2005. nlme: linear and nonlinear mixed effects models. R package version 3.1-85.

Plasqui, G., Westerterp, K.R., 2004. Seasonal variation in total energy expenditure and physical activity in Dutch young adults. Obesity Research 12, 688-94. 
R Development Core, T., 2004. R: a language and environment for statistical computing. R Foundation for Statistical Computing, Vienna, Austria.

Randrianambinina, B., Rakotondravony, D., Radespiel, U., Zimmermann, E., 2003. Seasonal changes in general activity, body mass and reproduction of two small nocturnal primates: a comparison of the golden brown mouse lemur (Microcebus ravelobensis) in Northwestern Madagascar and the brown mouse lemur (Microcebus rufus) in Eastern Madagascar. Primates 44, 321-31.

Sardon, J.P., 2007. The 2003 heat wave. Eurosurveillance 12, 226.

Schwimmer, H., Haim, A., 2009. Physiological adaptations of small mammals to desert ecosystems. Integrative Zoology 4, 357-366.

Seguy, M., Perret, M., 2005. Factors affecting the daily rhythm of body temperature of captive mouse lemurs (Microcebus murinus). Journal of Comparative Physiology BBiochemical Systemic and Environmental Physiology 175, 107-15.

Terrien, J., Ambid, L., Nibbelink, M., Saint-Charles, A., Aujard, F., 2010. Non-shivering thermogenesis activation and maintenance in the aging gray mouse lemur (Microcebus murinus). Experimental Gerontology.

Terrien, J., Zahariev, A., Blanc, S., Aujard, F., 2009a. Impaired Control of Body Cooling during Heterothermia Represents the Major Energetic Constraint in an Aging Non-Human Primate Exposed to Cold. PLoS One 4, e7587.

Terrien, J., Zizzari, P., Bluet-Pajot, M.T., Henry, P.Y., Perret, M., Epelbaum, J., Aujard, F., 2008. Effects of age on thermoregulatory responses during cold exposure in a nonhuman primate, Microcebus murinus. American Journal of Physiology - Regulatory Integrative and Comparative Physiology 295, R696-703.

Terrien, J., Zizzari, P., Epelbaum, J., Perret, M., Aujard, F., 2009b. Daily rhythms of core temperature and locomotor activity indicate different adaptive strategies to cold exposure in adult and aged mouse lemurs acclimated to a summer-like photoperiod. Chronobiology international 26, 838-53.

van Ooijen, A.M., van Marken Lichtenbelt, W.D., van Steenhoven, A.A., Westerterp, K.R., 2004. Seasonal changes in metabolic and temperature responses to cold air in humans. Physiology \& behavior 82, 545-53.

Van Someren, E.J., Raymann, R.J., Scherder, E.J., Daanen, H.A., Swaab, D.F., 2002. Circadian and age-related modulation of thermoreception and temperature regulation: mechanisms and functional implications. Ageing Research Reviews 1, 721-78.

Weinert, D., Waterhouse, J., 2007. The circadian rhythm of core temperature: effects of physical activity and aging. Physiology \& Behavior 90, 246-56.

Wright, G.L., 1976. Critical thermal maximum in mice. Journal of applied physiology 40, 683-7. 


\section{FIGURE CAPTIONS}

Figure 1: Heat-induced modulations in the daily patterns of $T_{c}$. Average (mean $\left.\pm S E M\right)$ daily rhythms of $\mathrm{T}_{\mathrm{c}}$ recorded in adult and aged mouse lemurs acclimated to LD (long days) or $\mathrm{SD}$ (short days) and exposed for 8 days to $25^{\circ} \mathrm{C}$ (gray curves) and 8 days to $34{ }^{\circ} \mathrm{C}$ (black curves).

Figure 2: Rapid increase of $T_{c}$ after heat exposure. Time-course of $T_{c}$ day (mean $\left.\pm S E M\right)$ measured over the 8-day period of exposure to $34{ }^{\circ} \mathrm{C}$ in adult and aged mouse lemurs acclimated to LD (long days) or SD (short days) in comparison to values at the exposure to 25 ${ }^{\circ} \mathrm{C} . \mathrm{D}=$ day. LME models were performed. The final models, i.e. including the significant effects, are shown for the tested parameter.

Figure 3: Daily organization of $T_{c}$ rhythm is altered during heat exposure. Averaged (mean \pm SEM) values (in min) of $\mathrm{T}_{\mathrm{c}}$ decrease onset $\left(\mathrm{H}_{\mathrm{decr}}-\right.$ left panel) and time of occurrence of minimal $\mathrm{T}_{\mathrm{c}}\left(\mathrm{H}_{\min }\right.$ - right panel) measured at $25{ }^{\circ} \mathrm{C}$ and $34{ }^{\circ} \mathrm{C}$ in adult and aged mouse lemurs acclimated to LD (long days) or SD (short days). Positive and negative values mean phase advances and phase delays, respectively, in reference to lights-on. LME models were performed. The final models, i.e. including the significant effects, are shown for the tested parameters. Post-hoc tests were performed to show the effects of heat exposure among adult and aged groups at both tested photoperiods (NS: Non significant; *: $p<0.05 ; * *: p<0.01$ ).

Figure 4: Daily organization of LA rhythm is altered during heat exposure. Averaged (mean \pm SEM) values (in min) of LA onset (left panel) and LA alpha (duration of activity, right panel) measured between $25{ }^{\circ} \mathrm{C}$ and the 8-day period of exposure to $34{ }^{\circ} \mathrm{C}$ in adult and 
aged mouse lemurs acclimated to LD (long days) or SD (short days). $\mathrm{D}=$ day. LME models were performed. The final models, i.e. including the significant effects, are showed for the tested parameters.

Figure 5: Modulations in water turnover during heat exposure. Mean $( \pm S E M)$ values (in $\mathrm{g}$ / day) of water turnover measured in adult and aged mouse lemurs acclimated to LD (long days) or SD (short days) and exposed to 25 and $34{ }^{\circ} \mathrm{C}$. LME models were performed. The final models, i.e. including the significant effects, are shown for the tested parameter. Posthoc tests were performed to show the effects of photoperiod among adult and aged groups, whatever the tested $T_{a}(N S:$ Non significant; *: $p<0.05)$.

Figure 6: Heat-induced variations of IGF-1 levels. Mean $( \pm$ SEM) values (in $\mathrm{ng} / \mathrm{ml} * 100$ g BM) of IGF-1 levels corrected with body mass (BM) and measured at $25{ }^{\circ} \mathrm{C}$ and after 2 or 8 days at $34{ }^{\circ} \mathrm{C}$ in adult and aged mouse lemurs acclimated to LD (long days) or SD (short days). $\mathrm{D}=$ day. LME models were performed. The final models, i.e. including the significant effects, are shown for the tested parameter. Post-hoc tests were performed to show the effects of photoperiod among adult and aged groups at each tested $T_{a}$ (NS: Non significant; *: $p<0.05 ; * *: p<0.01)$. 
Figure 1.
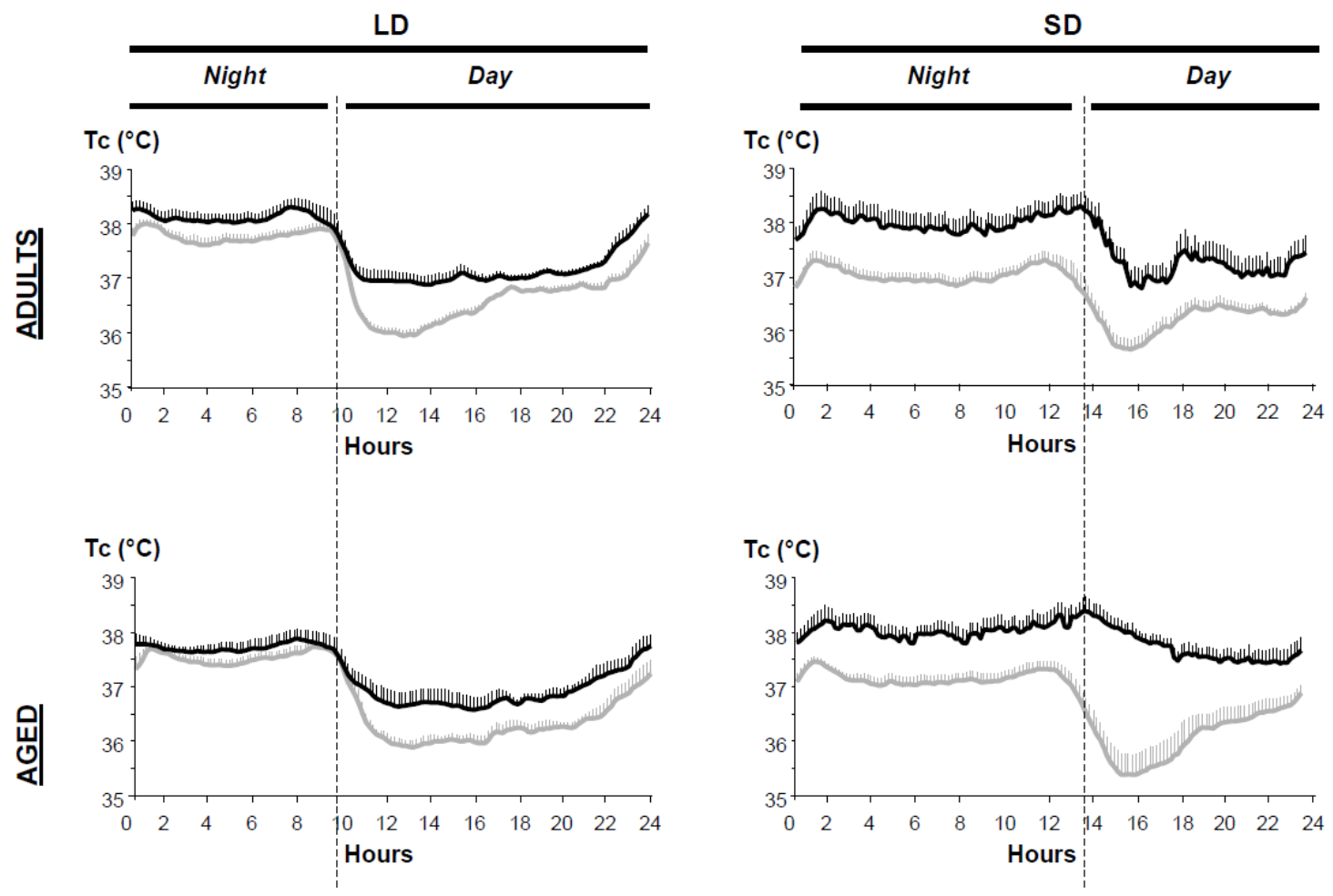
Figure 2.

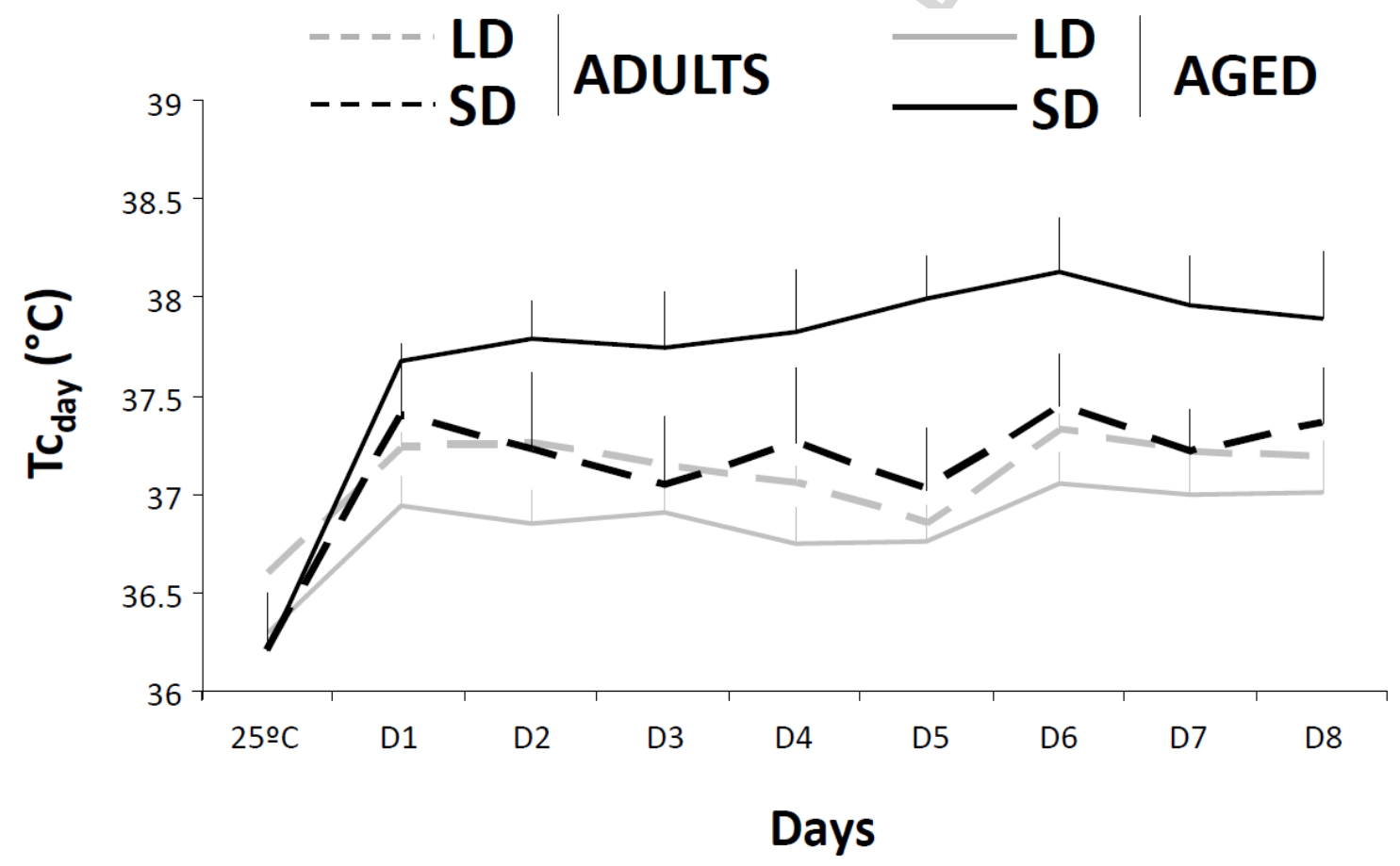

LME final model:

Tc $_{\text {day }}:$ Age $^{*} P_{\left(F_{(1,20)}=4.2, p<0.05\right)}+$ Duration $_{\left(F_{(7,160)}=3.2, p<0.01\right)}$ 
Figure 3.
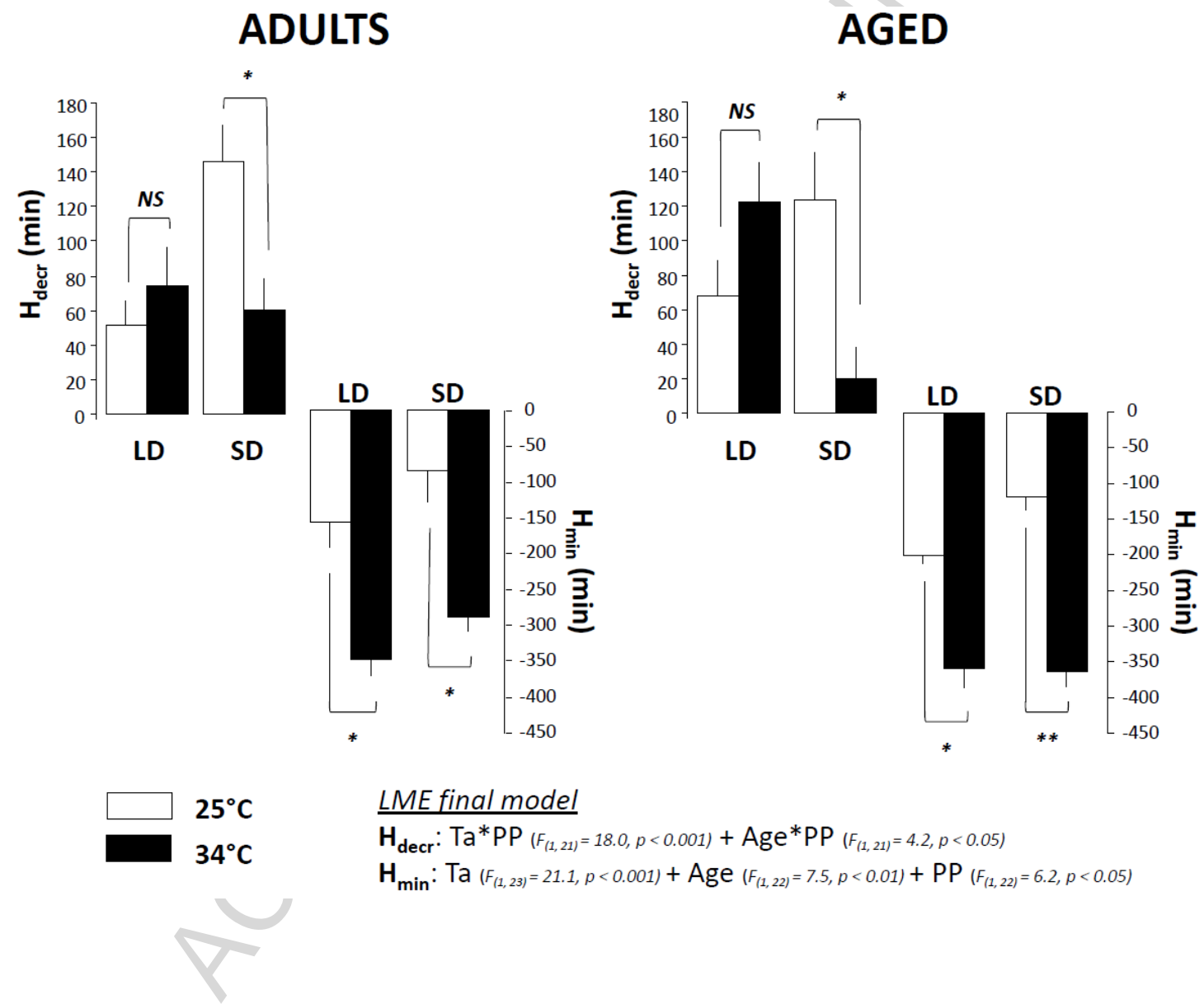

LME final model

$\left.\left.\mathbf{H}_{\text {decr }}: \operatorname{Ta}^{*} \operatorname{PP}_{\left(F_{(1,21)}\right.}=18.0, p<0.001\right)+\operatorname{Age}^{*} P_{\left(F_{(1,21)}\right.}=4.2, p<0.05\right)$

$\mathbf{H}_{\text {min }}:$ Ta $\left(F_{(1,23)}=21.1, p<0.001\right)+$ Age $\left(F_{(1,22)}=7.5, p<0.01\right)+\operatorname{PP}\left(F_{(1,22)}=6.2, p<0.05\right)$ 


\section{Figure 4.}
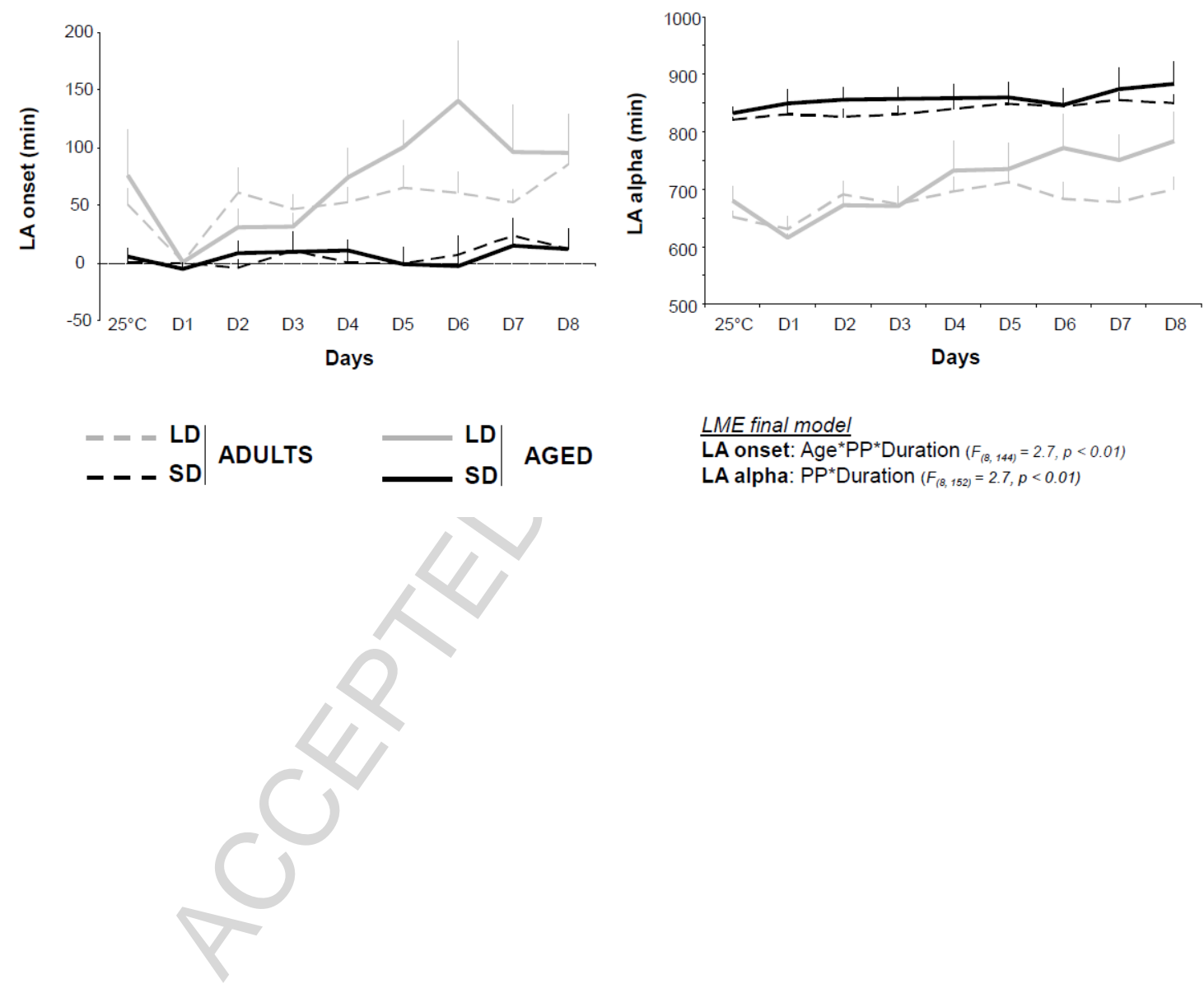

LME final model

LA onset: $A g e^{*} P P^{*}$ Duration $\left(F_{(8,144)}=2.7, p<0.01\right.$,

LA alpha: PP*Duration $\left(F_{(8,152)}=2.7, p<0.01\right)$ 
Figure 5.
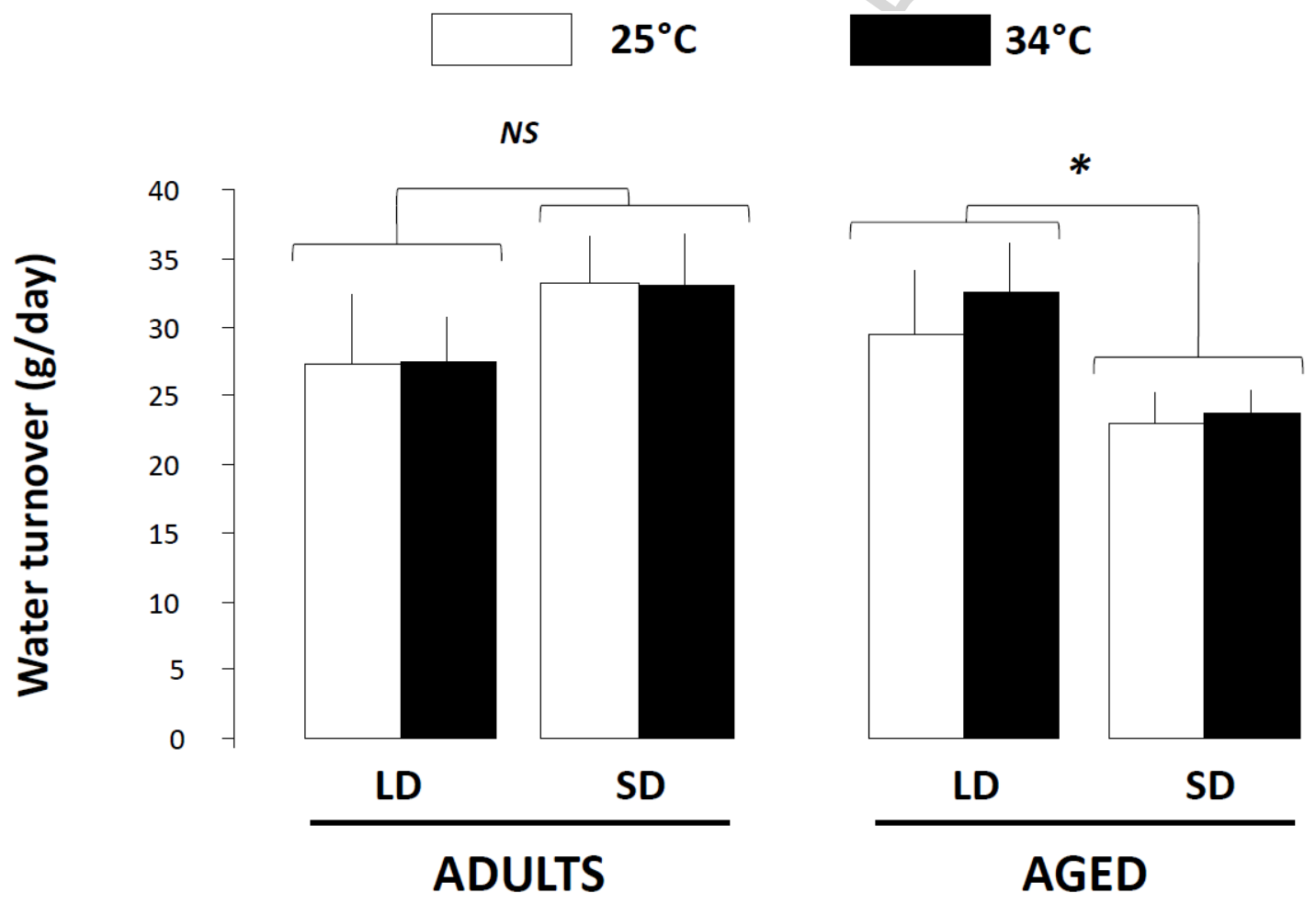

LME final model: Age*PP $\left(F_{(1,18)}=5.5, p<0.05\right)$ 
Figure 6.

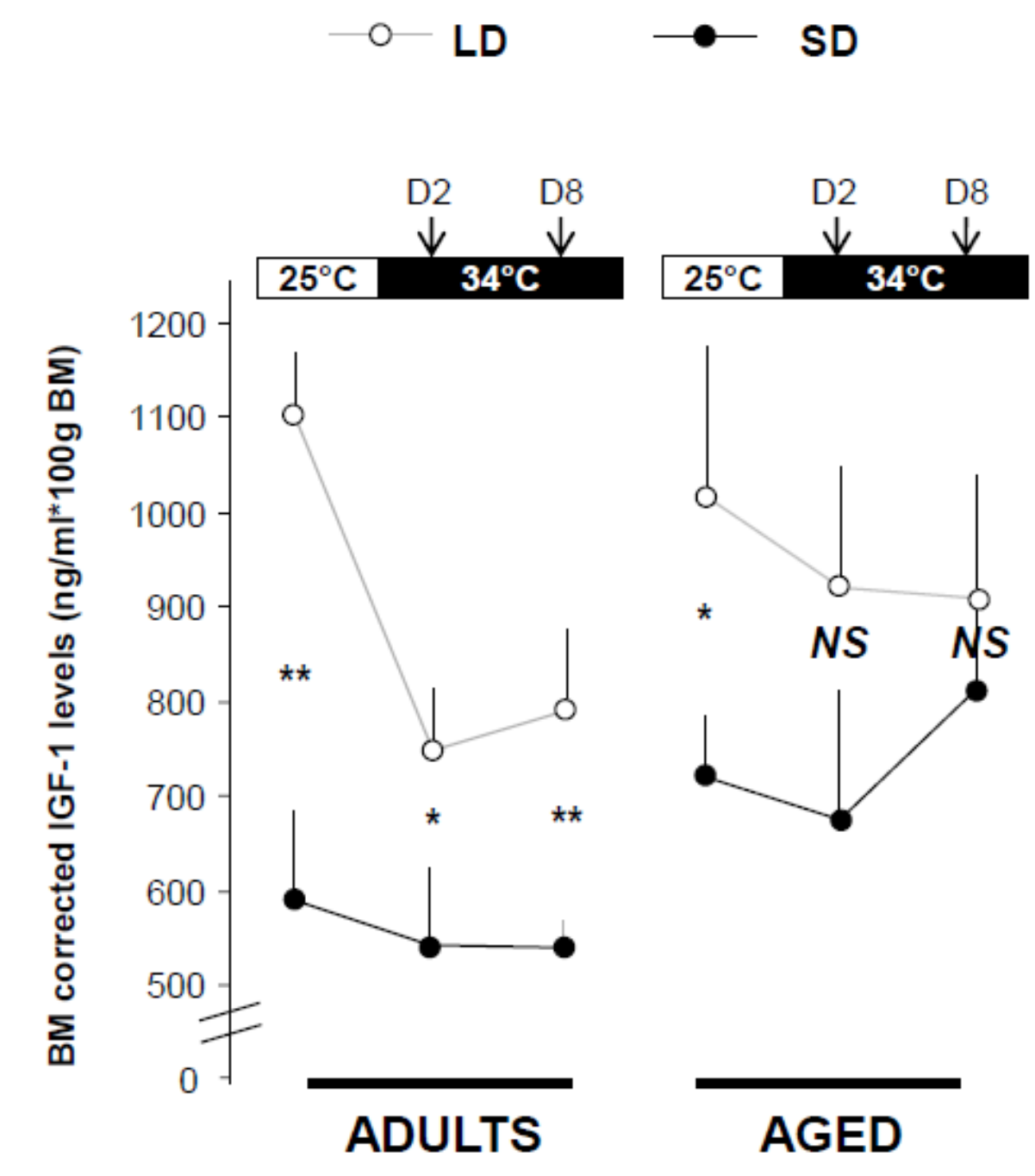

$\underline{\text { LME final model: }} \mathrm{Ta}\left(F_{(2,46)}=4.0, p<0.05\right)+\mathrm{PP}\left(F_{(1,21)}=6.8, p<0.05\right)$ 
Table 1. Parameters (means values \pm SEM) representative of nocturnal and diurnal levels of core temperature (Tc) at 25 and $34^{\circ} \mathrm{C}$ in adult and aged mouse lemurs acclimated to long days (LD) or short days (SD).

Abbreviations: $T c_{\text {night }}=$ nocturnal $T c ; T c_{\text {day }}=$ diurnal $T c ; T c_{\min }=\operatorname{minimal} T c ; T a=$ ambient temperature.

LME models were performed. The final models, i.e. including the significant effects, are showed for the tested parameters.

\begin{tabular}{|c|c|c|c|c|c|}
\hline Parameter & Age & PP & $25^{\circ} \mathrm{C}$ & $34^{\circ} \mathrm{C}$ & LME final model \\
\hline \multirow{4}{*}{$T c_{\text {night }}$} & \multirow{2}{*}{ ADULTS } & LD & $37.8 \pm 0.1$ & $38.1 \pm 0.2$ & \multirow{4}{*}{$\begin{array}{c}\mathrm{Ta}^{*} \mathrm{PP} \\
F_{(1,22)}=17.5, p<0.001\end{array}$} \\
\hline & & SD & $37.0 \pm 0.1$ & $38.0 \pm 0.3$ & \\
\hline & \multirow{2}{*}{ AGED } & LD & $37.5 \pm 0.1$ & $37.7 \pm 0.2$ & \\
\hline & & SD & $37.0 \pm 0.2$ & $38.1 \pm 0.2$ & \\
\hline \multirow{4}{*}{$T c_{\text {day }}$} & \multirow{2}{*}{ ADULTS } & LD & 36. $6 \quad 0.0$ & $37.1 \pm 0.1$ & \multirow{4}{*}{$\begin{array}{c}\mathrm{Ta}^{\star} \mathrm{PP} \\
F_{(1,22)}=10.5, p<0.01\end{array}$} \\
\hline & & SD & $36.2 \pm 0.1$ & $37.2 \pm 0.3$ & \\
\hline & \multirow{2}{*}{ AGED } & LD & $36.3 \pm 0.1$ & $36.9 \pm 0.2$ & \\
\hline & & SD & $36.2 \pm 0.3$ & $37.7 \pm 0.2$ & \\
\hline \multirow{4}{*}{$T c_{\min }$} & \multirow{2}{*}{ ADULTS } & LD & $35.8 \pm 0.1$ & $36.6 \pm 0.1$ & \multirow{4}{*}{$\begin{array}{c}\mathrm{Ta}{ }^{*} \mathrm{PP} \\
F_{(1,22)}=6.5, p<0.05\end{array}$} \\
\hline & & SD & $35.6 \pm 0.2$ & $36.7 \pm 0.3$ & \\
\hline & \multirow{2}{*}{ AGED } & LD & $35.8 \pm 0.1$ & $36.4 \pm 0.2$ & \\
\hline & & SD & $35.5 \pm 0.3$ & $37.2 \pm 0.2$ & \\
\hline
\end{tabular}


Table 2. Parameters (means values \pm SEM) representative of energy balance measured at 25 and $34{ }^{\circ} \mathrm{C}$ in adult and aged mouse lemurs acclimated to long days (LD) or short days (SD).

Abbreviations: $\mathrm{Cl}=$ caloric intake; $D E E=$ daily energy expenditure; $B M G=$ body mass gain; $\mathrm{Ta}=$ ambient temperature.

LME models were performed. The final models, i.e. including the significant effects, are showed for the tested parameters.

\begin{tabular}{|c|c|c|c|c|c|}
\hline Parameter & Age & PP & $25^{\circ} \mathrm{C}$ & $34^{\circ} \mathrm{C}$ & LME final model \\
\hline \multirow{4}{*}{$\begin{array}{c}\mathrm{Cl} \\
(\mathrm{kJ} / \mathrm{day} \\
* 100 \mathrm{~g} \mathrm{BM})\end{array}$} & \multirow{2}{*}{ ADULTS } & LD & $138 \pm 12$ & $114 \pm 21$ & \multirow{4}{*}{$\begin{array}{c}\mathrm{Ta} \\
F_{(1,24)}=30.6, p<0.001\end{array}$} \\
\hline & & SD & $143 \pm 22$ & $81 \pm 10$ & \\
\hline & \multirow{2}{*}{ AGED } & LD & $131 \pm 15$ & $89 \pm 13$ & \\
\hline & & SD & $123 \pm 9$ & $68 \pm 14$ & \\
\hline \multirow{4}{*}{$\begin{array}{c}\text { DEE } \\
\text { (kJ/day } \\
* 100 \mathrm{~g} \mathrm{BM})\end{array}$} & \multirow{2}{*}{ ADULTS } & LD & $118 \pm 14$ & $64 \pm 8$ & \multirow{4}{*}{$\begin{array}{c}\mathrm{Ta} \\
F_{(1,20)}=14.7, p<0.001\end{array}$} \\
\hline & & SD & $84 \pm 10$ & $53 \pm 12$ & \\
\hline & \multirow{2}{*}{ AGED } & LD & $91 \pm 10$ & $60 \pm 7$ & \\
\hline & & SD & $83 \pm 11$ & $57 \pm 6$ & \\
\hline \multirow{4}{*}{$\begin{array}{l}\text { BMG } \\
\text { (g/day) }\end{array}$} & \multirow{2}{*}{ ADULTS } & LD & $0.1 \pm 0.1$ & $0.6 \pm 0.4$ & \multirow{4}{*}{$\begin{array}{c}\text { Age }^{\star} \mathrm{PP} \\
F_{(1,21)}=4.5, p<0.05\end{array}$} \\
\hline & & SD & $1.4 \pm 0.2$ & $1.4 \pm 0.3$ & \\
\hline & \multirow{2}{*}{ AGED } & LD & $0.3 \pm 0.5$ & $0.4 \pm 0.5$ & \\
\hline & & SD & $0.5 \pm 0.2$ & $-0.2 \pm 0.4$ & \\
\hline
\end{tabular}

